\title{
Application of Big Data Analysis Technology in Cross-Border E-Commerce
}

\author{
Yanan Song* \\ University of California, Irvine, The United States of America \\ *Corresponding author: Yanan Song, 6651118@163.com
}

\begin{abstract}
Under the background of national development strategy in the new era, cross-border e-commerce with the help of Internet platform can realize the interconnection between producers and consumers, and gradually expand the influence of international trade. Based on big data technology, this paper builds an industry chain with cross-border e-commerce members' participation, and analyzes the specific application of big data in the product support, internal operation, external marketing, logistics service and service evaluation of cross-border e-commerce industry chain. The purpose is to effectively promote the healthy development of cross-border e-commerce and improve China's trade and economic level.
\end{abstract}

Keywords: Big data; Cross-border e-commerce; E-commerce

Publication date: July 2021; Online publication: July 31, 2021

\section{Introduction}

Based on the perspective of the industry chain, using big data to study cross-border e-commerce and discover new economic growth points has become a new value demand for cross-border e-commerce development in the era of big data. The drive of big data technology plays an important role in cross-border e-commerce transactions. Its application value and ideas are mainly reflected in the five major links of the cross-border e-commerce industry chain: product support, internal operations, external marketing, crossborder logistics and service evaluation (Figure 1.).

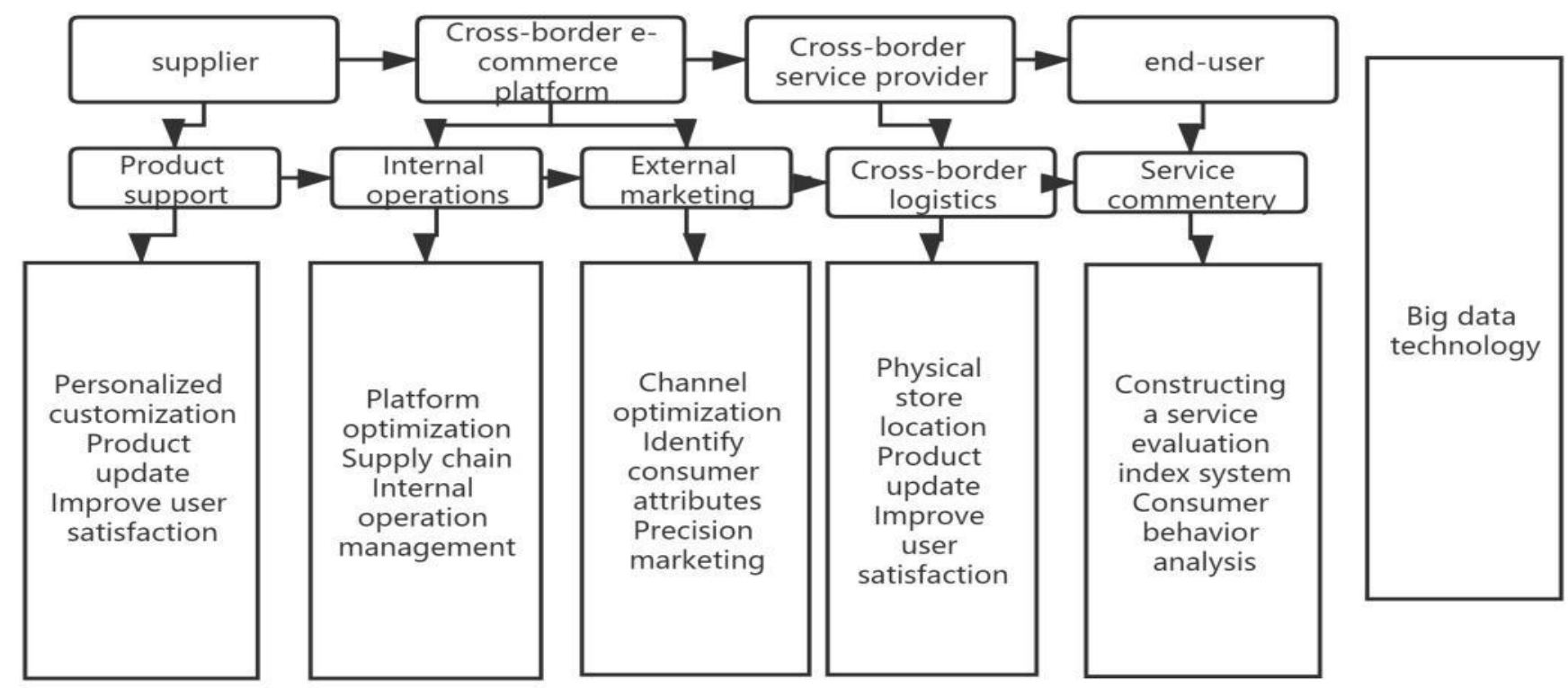

Figure 1. Application framework model of cross-border e-commerce industry chain based on big data technology 


\section{Product Support}

The effective combination of big data and product support has become a key means for suppliers to enhance product competitiveness. As the core support of products, the function embodied by big data is to be able to analyze customer's personalized demand information for products, carry out personalized design of products, meet the personalized needs of users, provide differentiated services, and expand differentiated markets. In addition to the economic activities of the enterprise, another very important application path is to improve and optimize the product itself through the unified needs and suggestions of customers for the product, so that the update of the product highly meets the needs of customers, thereby improving crossborder electricity ${ }^{[1]}$. The satisfaction rate of core users of commercial products improves the economic benefits of cross-border e-commerce companies.

\section{Internal Operations}

Cross border e-commerce is the product of the combination of foreign trade and information technology, and its development is inseparable from the construction of internal support conditions. At the internal operation level, the information service function design of cross-border e-commerce platform tends to be convenient and diversified driven by big data technology. From the perspective of cross-border e-commerce platform optimization, cross-border e-commerce enterprises can make full use of big data to optimize their own websites, adjust the information function of cross-border e-commerce platform, ensure that the content of the web page is more detailed and substantial, enrich consumers' perception of products when purchasing, and avoid the limitations of the original traditional manual data processing, such as lag, low efficiency and distortion ${ }^{[2]}$. From the perspective of supply chain management efficiency, based on big data technology, the sources of enterprise source information tend to be diversified. Cross border e-commerce enterprises need to rely on big data technology to determine the key factors of supply chain efficiency, and make reasonable design and arrangement according to the key factors, so as to improve the operation efficiency of cross-border e-commerce enterprises' supply chain as far as possible.

\section{External marketing}

In the external marketing link, cross-border e-commerce companies can identify user attributes based on big data technology and formulate reasonable and targeted marketing strategies. Cross-border e-commerce companies can distinguish whether users are long-term customers or potential customers based on the relevant big data of users on the cross-border e-commerce platform, and then develop marketing strategies that meet their characteristics for different users based on user attributes, and establish a good relationship with users. The cooperative and interactive relationship achieves a win-win situation for both parties in the transaction (Figure 2.).

\section{Cross-border logistics}

With the advent of the "big data" era and the continuous development of cross-border e-commerce, the combination of big data technology and cross-border logistics has also become an inevitable trend of development. Using big data analysis technology to reasonably select physical store locations, establish a data analysis management system based on logistics data, and select the most suitable delivery method according to the time and address of the user's receipt of goods to provide customers with high-quality logistics services. In addition, in response to the information feedback from the big data of cross-border ecommerce logistics, cross-border e-commerce companies can adjust the number and location of commodity storage, increase the storage of popular commodities in hot-selling regions, and reduce the storage of unsalable commodities in unpopular regions. 


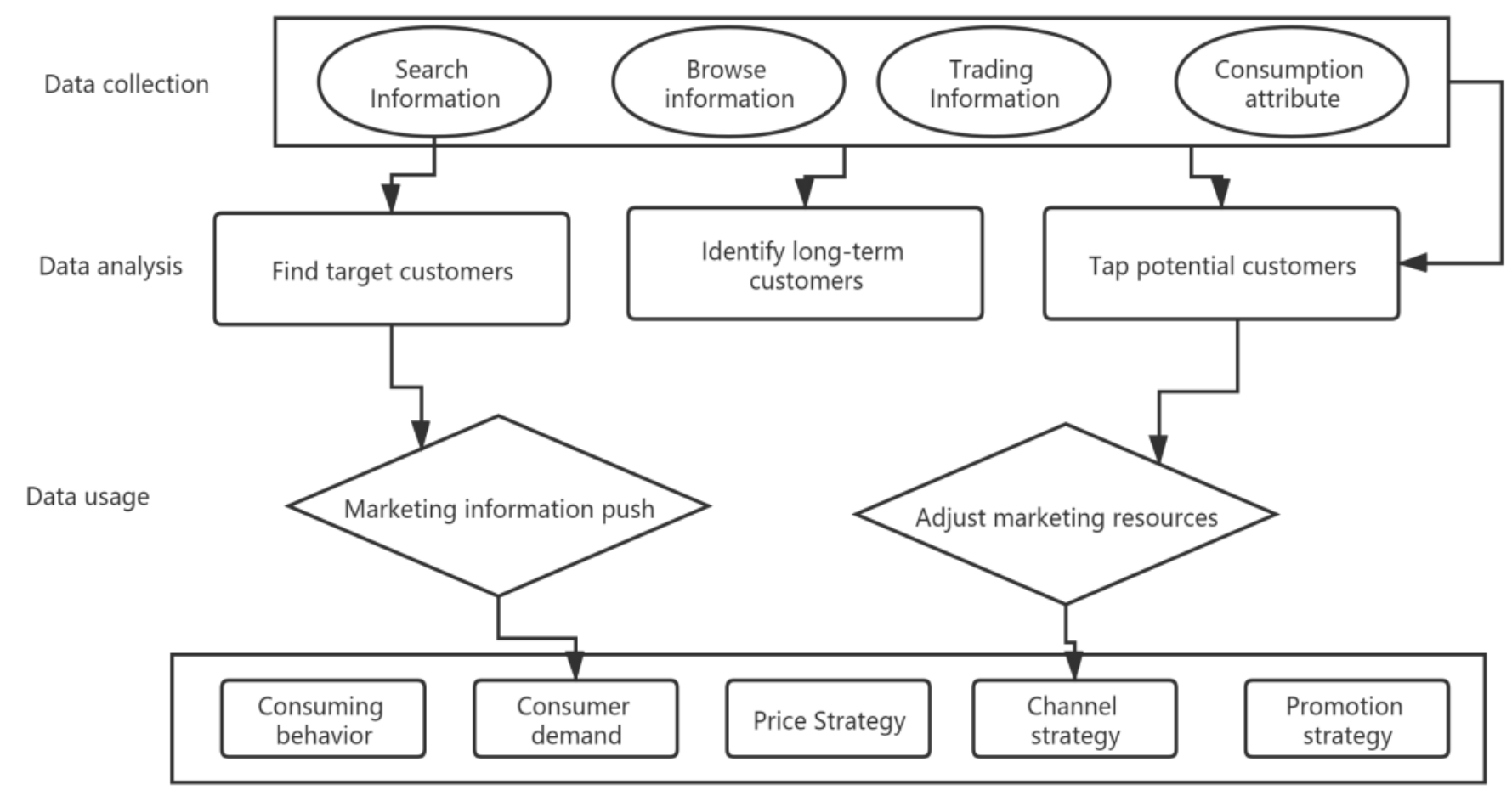

Figure 2. Application of Big Data Technology in External Marketing

\section{Service commentary}

Combined with the actual situation of cross-border e-commerce in China, from the perspective of service process of cross-border e-commerce, we make full use of the Internet and big data to design, build the crossborder e-commerce service evaluation index system, and further improve the cross-border e-commerce service management mechanism and government supervision ${ }^{[3]}$. Based on the perspective of consumers, the big data technology is used to analyze the service experience and evaluation of consumers on crossborder e-commerce, so as to analyze the behavior of customers in cross-border e-commerce platform and study the consumer psychology of cross-border e-commerce users, so as to make it easier to lock in potential customers and provide personalized services

\section{Disclosure statement}

The author declares no conflict of interest.

\section{References}

[1] Ma G, n.d., Research and Application of Operational Model in Cross-border E-commerce Based on Big Data Technology, Institute of Management Science and Industrial.

[2] Engineering, 2019, Proceedings of 2019 7th International Conference on Machinery, Materials and Computing Technology (ICMMCT 2019). Institute of Management Science and Industrial.

[3] Engineering, 2019, Computer Science and Electronic Technology International Society, 4. 